\title{
KSENIA O. PROSYUKOVA ${ }^{1}$
}

\section{THE ETHICS OF THE SYRIAN MIGRATION CRISIS}

\begin{abstract}
The Syrian migration crisis is one of the biggest social crises of the modern era. This is evidenced by the geographical spread of the consequences, the number of refugees in each of the host countries and other bare statistics. In the context of this crisis, the governments of the host countries are making efforts to solve many problems related to the political status of refugees, their psychological adaptation to new surroundings, economic challenges for the host countries, along with issues connected with the integration and socialization of migrants. However, not many of us think about the ethical side of the migration process. Moreover, sometimes such aspects as the violation of human rights, confrontation between the ethical principles of Islam and the secular culture of Europe, and confrontation between Christian and Islamic values are simply ignored. Nevertheless, all these "inconvenient" topics are breeding grounds for concentrating misunderstandings and developing zero tolerance towards migrants, and which have an impact on the overall outcome. The migration crisis is not a temporary "inconvenience," not a desperate measure, it is a process of transformation of European society. We consider this process as a social evolution that can be in the best interest of all participants. However, this process is impossible without reaching a compromise on ethical issues. This article is devoted to examining the ethical dilemma of the migration crisis and finding ways of solving it.
\end{abstract}

Keywords: ethics, migration, Syria, refugees, crisis, ethical problems, migrants

\section{INTRODUCTION}

Few people have ever thought how stressful forced migration is for an individual. On a scale from 0 to 10 , psychologists estimate the level of stress for a migrant at around 9, i.e. almost the maximum level. In order to illustrate

${ }^{1}$ Dr.; Kazan Federal University; ORCID: 0000-0002-8567-4658;

prokseniya@mail.ru. 
this indicator more clearly, it makes sense to add that this is the same level of stress experienced by a person who has lost a family member or finds out about a fatal medical diagnosis. In both such cases, society is ready to react - there are psychological aid programs, a code of ethics used by medical specialists in working with patients who have learned about a fatal diagnosis, as well as unspoken ethical principles accepted by members of society that somehow clearly regulate behavior patterns in communication, enabling us to show empathy, provide support and assistance. In the case of migrants, and especially forced migrants (refugees), the situation is completely different. In the process of numerous interviews that we conducted at different stages of this study, mainly related to analyzing the process of adaptation of Syrian refugees to a new social environment, we were able to identify the prevailing views regarding migrants that exist in society as:

- migrants are burden for the economy;

- migrants create risks for the social well-being of the country;

- migrants are the major factor that increases the crime rate, etc.

On the positive side, the general perception of migrants is not limited to only negative connotations: some of the respondents mentioned the potential migrants create for the development of new industries; the productive effect of the exchange of cultures; the emergence of new directions in art, etc. In general, however, these concerned evaluative judgments of the host society (in this context we consider the inhabitants of Europe as members of the "host community;" thereafter, there is potential for further specific research of a number of countries that have accepted the largest number of refugees).

The aim of this study is to analyze the ethical component of the migration issue. To achieve this aim, we identified four key objectives, namely:

1. to provide a definition of ethics in the context of cross-cultural interaction of migrants and members of the host society.

2. to identify the key markers of the image of a migrant as part of an associative experiment based on a series of detailed interviews.

3. to consider the key factors affecting the formation of the image of a migrant in the minds of members of the host society, as well as the emergence of prejudices and stereotypes.

4. to formulate an ethical dilemma and suggest possible ways to resolve it. 


\section{METHODOLOGICAL FRAMEWORK}

At the first stage of our research, we considered the existing definitions of ethics, examined the existing approaches to detailing ethical knowledge, as well as types of ethics, all of which allowed us to propose a definition of ethics in the context of the migration crisis through the application of the analytic-synthetic method.

At the second stage, we conducted an associative experiment with the purpose of determining the key characteristics of the image of migrants in modern society. In total, 124 volunteers, namely adult respondents living in different countries who, according to the UN data, had experienced the effects of the migration crisis, took part in the experiment. The experiment was conditionally divided into two stages: at the first stage, the respondents had to offer associations that instantly appeared when they perceived auditory (by ear) information (the words "migrant," "refugee," "Syrian," "female migrant," "refugee child," "migrants," "refugees," "Syrians") and visual information (sound-off television reports on migrants, photographs from magazines and newspapers without text). At the second stage, a series of detailed interviews with respondents made it possible to determine the presence/absence of personal experience of interaction with migrants, as well as the resources for obtaining basic information about the situation concerning migrants in their country.

At the third stage of the study, we analyzed 37 sources (popular newspapers and magazines in different countries of the EU and the Middle East), selected by random sampling, for the publication of materials that could contribute to the negative stereotyping of the image of migrants. The indicator of the frequency of publication of materials in the media was also taken into account (what percentage of articles of all materials published about migrants contains evaluative judgments that can form a negative image of a migrant in society).

At the fourth stage, we presented the concept of the "ethical dilemma" existing in the context of the migration crisis, and suggested possible ways to resolve ethical contradictions. 


\section{RESULTS}

\subsection{DEFINITION OF ETHICS IN THE CONTEXT OF THE MIGRATION CRISIS}

In philosophy, the perception of ethics is reduced to the concept of virtue itself (Bartlett et al. 2012, 27). In the modern sense of the term, ethics is a philosophical school of thought that studies morality as one of the most important aspects of the life both of an individual and society. If morality is an existing specific phenomenon of social life, then ethics as a science theoretically substantiates a certain moral system by studying morality, its essence, nature and structure, the laws of occurrence and development, and its place in the system of other social relations.

Historically, the object of ethics has changed significantly. Since it developed as a school for educating the individual, teaching them virtues, it was, and still is considered (by religious ideologists) as a person's exhortation for the fulfillment of divine covenants that ensure the immortality of that person. It is characterized as a doctrine of incontestable duty and the ways of its fulfillment, as well as a source of knowledge on the formation of a "new man" - a selfless developer of an absolutely just society, etc. (Lippmann 1921, 78). Ethics as a science not only studies, generalizes and systematizes the principles and norms of morality that are applicable by society, but also contributes to the development of such moral ideas that meet historical needs to the maximum extent, thereby contributing to the development of society and the individual as a member of this society. Ethics, as a science, serves the social and economic progress of society and the adoption of the principles of humanism and justice in it.

The word "ethics" was formed by Aristotle from the word "ethos," which had several meanings in ancient times. Ethos in its first meaning is a habitat, a dwelling, an animal den. Later, it began to denote the stable nature of a certain phenomenon, a custom, just a habit, temper or character (Bartlett et al. 2012, 67-69).

It is important to see two major connotative meanings of the word ethos, preserved at the present time:

- the first meaning of ethos is a qualitative characteristic of society, namely the mores, habits, customs inherent in a particular ethnos, or the nature of a nation, predetermined by the "place" constituting its habitat. This is the definition of ethos as characterized by cultural anthropology and ethnography. In this sense, we can talk about European, Russian, Japanese ethos, and so on; 
- the second meaning of the word ethos - the character and fate of an individual - was developed in traditional ethics. Its object is the individual him/herself, their individual moral problems and values, their rationality and ability to solve any problems independently (Bartlett et al. 2012, 67-69).

In general, ethics represents a combination of different types:

- professional ethics, as a set of certain principles and rules that are observed by specialists from the same professional field in relation to each other; a kind of solidarity and unconditional support. As examples of professional ethics, we can list business ethics, medical ethics, ethics of translators, lawyers, etc.;

- applied ethics, namely a set of principles, norms and rules that perform, on the basis of normative ethics, the practical function of teaching people proper behavior in specific situations and in certain areas of their life. As examples of ethical problems that fall under the definition of applied ethics, we can list euthanasia, the issue of gay marriage, the right to abortion, the use of the death penalty as a form of capital punishment, etc. (Habermas 1983, 126).

However, more and more frequently scholars insist that there is a need for a detailed examination of the concept of "applied ethics" in such areas of philosophy as:

- environmental ethics as norms of individual behavior in relation to the environment;

- civil ethics as norms of behavior of an individual in relation to society;

- situational ethics, which often comes down to the concept of "etiquette," namely the norms and traditions of behavior depending on the communicative situation and aspects of the social environment;

- social ethics, which considers concepts such as social institutions, social morality, social justice, social responsibility, philanthropy, patriotism, cosmopolitanism, social trust, etc.

As we can see, none of the existing concepts of ethics fully complies with ethics in the context of the migration issue. On the one hand, ethical principles governing the perception and interaction of "aliens" with the members of the "host society" combine aspects of civil ethics (statement "a migrant is (not) a citizen of a country, and therefore can (not) have proper patriotic feelings about my state, remain indifferent to its problems, make efforts to create a common good and act in the interests and for the 
development of the state) and social ethics (such statements as "an alien can (not) be trusted," "an alien should (not) have access to social welfare [education, medicine, social assistance, etc.]").

Therefore, our present understanding of ethics in the context of the socialization of migrants should be reviewed and supplemented. Another problem is the perception of socialization as a process that is more often perceived as a mechanism of achieving conformity and adaptation of an individual to the norms, requirements and views of society. This ultimately contradicts the actual concept of "socialization," which includes not only the process of assimilation of norms, rules of behavior, values, knowledge and skills, but also the process of integration of the individual by achieving harmony in new conditions and a sense of comfort in the process of communication with members of the new society, gaining confidence that, as a member of this society, he or she is needed, required and has equal opportunities for self-development.

Thus, considering ethics in the context of migration issues, we can define this as a set of norms, principles and rules of behavior within the interaction of an individual and society in a new social and cultural environment, as well as with members of the same (or other) "alien" culture.

\subsection{SteReOtyping AND tHe IMAGE OF "A MigRANT" (ASSOCIATIVE EXPERIMENT)}

The formation of stereotypes and prejudices is a protective function of our psyche, which in the process of evolution was supposed to protect society from the harmful effects of any alien culture; a mechanism that helps one to form an idea based on already existing beliefs and ideas that all members of the same society have about an object. To consider the process of formation of stereotypes from the point of view of existing theories of cross-cultural communication, we should review several different ways that stereotypes are formed:

- Stereotypes that are absorbed in the process of enculturation. In any culture, there are stereotypes regarding other cultures. First of all, stereotypes are formed about groups of people representative of this culture with whom they interact and/or are in mostly conflict (or have been in the past). Such stereotypes are passed down from generation to generation, from parents to children;

- Stereotypes that are formed in the process of communication with significant others: relatives, friends, teachers, etc.; 
- Stereotypes that arise as a result of personal contacts with individual representatives of an alien culture;

- The media also has an enormous impact on emergence of stereotypes (to be considered further). Most people identify television, press and radio as authoritative sources of information that shape social perception of a particular culture (McGarty 2002, 47).

At the present stage of social development, we are increasingly confronted with the statement "stereotyping (emergence of stereotypes) is a negative process that forces attribution (of certain qualities that are not directly presented in the current communicative situation and never occurred at the previous cases of contact), thereby depriving the participants in the communication process of freedom of communication and impartiality, creating barriers and obstacles to communication.

In fact, most experts in the field of cross-cultural communication hold the opinion that it is necessary to separate "stereotypes" and "prejudices." Prejudice as the setting of a biased and hostile attitude towards something/somebody without sufficient grounds is, of course, a factor that can potentially create obstacles for the successful communication between members of different social or cultural groups. Moreover, prejudices become an indirect cause of estrangement and even hatred. However, stereotypes constitute only a set of basic knowledge about a cultural or social group, which (as a rule) is generally not negative and, on the whole, reflects some common features of the members of the same group. The existence of stereotypes itself does not become an obstacle for the development of successful communication. It makes more sense to analyze the process of managing stereotypes, which is a three-stage process, namely: the awareness of stereotypes - the deactivation of negative stereotypes the actualization of positive stereotypes.

As part of our study, one of the key tasks we identified as the need to analyze the existing "image of a migrant." By "image" we considered a certain general stereotypical idea of migrants (and refugees) among members of the host culture. In the context of "stereotype awareness" we carried out one of the most effective experiments of our analysis, which was an associative experiment. This experiment was only the first attempt to analyze the "image of a migrant" and has huge potential for further development. At the first stage, we selected 124 volunteers who agreed to take part in the experiment. These 124 individuals were adults with different background from different countries - students, professors, housewives, 
etc. We asked them to give instant associations for a word "migrant" we did not indicate anything else - sex, ethnicity, age. Thus, we got such answers as "man" (92), "criminal" (87), "someone who doesn't speak my language" (78), "Arab" (76), "terrorist" (54), "Islamist" (50), "different" (49), "African" (46), "guest" (34), and so on. This is a simple example of what we feel about migration: we see migrants as a threat to our safety, our principles, the civil order, our culture and traditions.

Furthermore, we asked our respondents to imagine a "female refugee" or "a minor refugee" and got much softer answers with the expression of empathy: "poor" (101), "mother" (100), "homeless" (98), "beggar" (96), "Arab" (65), "different" (43), etc.

The associative experiment vividly demonstrates that the depersonalized concept of "migrant" creates clearly negative associations in the minds of the members of the host society. However, as soon as the concept is supplemented with more information (gender, age, profession), negative associations are leveled, the associative field shifts to softer wording. Therefore, if we understand what affects the formation of a negative associative field of the concept of "a migrant," we can then figure out which components of the stereotype can be deactivated and which can be activated in order to ensure communication and the successful integration of migrants into their new environment.

\subsection{Key factors afFeCting formation of Collective image of "A MIGRANT"}

There are numerous factors that contribute to stereotyping and affect the formation of a collective image of "a migrant." Nearly all of them come down to two categories, namely "sensory experience" (personal communication with members of a group, perception of cultural objects (cinema, literature), historical memory) and "social commissioning." And if the first category is quite difficult to regulate, and the processes of formation of stereotypes are very chaotic and often quite personalized, then the second category is much more interesting to researchers, and the very concept of "social commissioning" needs to be clarified.

Generally speaking, "social commissioning" refers to a social need that is relevant to society as a whole. It can be related to performance of intellectual work, for example, in the field of art or culture, taking into account the ideological orientation of the official policy of the state (Meteley 2010). We can refer art to the so-called provider of social attitudes: the Russian 
writer Maxim Gorky was one of those who mentioned the "educational potential of literature." Although today we would probably discuss the major potential of cinema, the dominant role in formation of social stereotypes, of course, is assigned to the media. For this reason, in the framework of the undertaken analysis, we decided to study what impact media has had on formation of the collective image of "a migrant" in recent years.

Turkey was among those countries that hosted the largest community of Syrians displaced by the ongoing conflict: in August 2015 the Turkish Ministry of Interior Affairs stated that 1,905,000 had already arrived. According to a report that examined 177 news articles, only three cited Syrian refugees' opinions. The Turkish newspaper Hü rriyet, for example, published eight articles during a year that related refugees to social tension, rent increases and rising unemployment. The articles mostly addressed the refugee question as a security issue, talking about measures against public-order disruption. In most cases refugees were identified with crime, sex work and begging. The media, while seemingly asking citizens to "tolerate" these "visitors," failed to cover the issue from a rights-based perspective (Moving Stories 2015).

We can also address the UK with the same issue: as part of global media coverage of the tragic events that united hundreds of migrants who drowned off the coast of Italy, The Sun columnist Katie Hopkins wrote: "I don't care. Show me pictures of coffins, show me bodies floating in water, play violins and show me skinny people looking sad. I still don't care... these migrants are like cockroaches... they are built to survive a nuclear bomb. They are survivors." The Daily Express some months before that published 22 negative front pages stories about asylum seekers and refugees in a single 31-day period (Moving Stories 2015).

Another country where migration is not just a newspaper story, but the sad reality, is Lebanon which has the most refugees, with every third person being a Syrian refugee. In January 2018, the Lebanese daily newspaper Annahar published scorching criticism by Hussein Hazoury who said Hamra Street, Beirut's one-time Champs Elysées, had changed color from "hamra" (red) to "sawda" (black) with the unregulated influx of (darkskinned) Syrians. He complained that the street had lost its charm, that the Syrian presence had changed Hamra's demography, and that restaurant owners were decrying the proliferation of cheap Syrian labor and competition from Syrian eateries. Dina Moukalled, a Lebanese reporter says: "Media usually deal with refugees as a block and not as individual stories. 
There is some good coverage, but that does not represent the mainstream media" (Moving Stories 2015).

As we can see, despite the general ideology of tolerance, the media nevertheless actively forms a negative image of a "migrant," which inevitably leads to the actualization of a negative stereotype, which afterwards creates obstacles for positive communication between migrants and members of the host society, as well as the successful integration of migrants into their new environment.

\section{4. "Ethical dilemmas" and the migration issue}

As a part of a psychological experiment, we proceed to the ethical component of the migration crisis. In the course of numerous interviews that we conducted at the stages of analyzing the process of integrating refugees into a new educational environment, we came to the conclusion that key ethical problems arise due to the basic beliefs that exist in society and are formed on the basis of stereotypical ideas about migrants, that are being actualized, among others, by the media:

- We treat migrants and refugees as a "temporary phenomenon," a kind of "inconvenience" that disrupts the usual course of things, becoming a threat to our values, traditions and self-identification. It makes sense, therefore, to perceive migration as a process of global social change, one of the stages of globalization, the social evolution, which is also facilitated by economic and political transformations: the definition of "borders" between countries is being erased, economic and political unions and alliances are appearing, contributing to rapprochement of countries, cultural interaction creates potential for the development of new, related areas in science and art. When the situation in Syria (and other crisis regions) becomes stable, most of the current migrants and refugees will not return home (as evidenced by statistics - most of the labor migrants from Turkey settled in Germany, although initially the engagement of Turkish specialists was seen as a temporary solution ).

- The existing programs for integration and adaptation of refugees and migrants are based on the idea of introducing migrants to the culture of the host country, its norms and rules of behavior, traditions and customs, thereby adapting the migrants themselves, changing them in accordance with our expectations and ideas. A counter-process of 
adaptation of the members of the host society to changing reality could be a more productive tactic. The position "a foreign culture does not threaten my identity, does not aim to destroy my values and views, but, on the contrary, creates the potential for discovering my own culture in the process of cultural exchange" contributes to greater openness, understanding and communication.

- The above-mentioned associative experiment proved that a negative association was mainly formed when a respondent heard the plural form of the word "migrant" (migrants). When we consider migration as something impersonal, we form the negative attitudes of the members of the host society. This group often associate migrants as a group with danger, risks to their normal life style, the cause of crime. In the media, all information about migrants is more often presented in the form of statistical summaries, where we do not notice the people behind figures and percentages. At the same time, many of our respondents noted that there was a person (a friend, a neighbor, a colleague) in their immediate circle, who is a migrant or refugee, who is in a good relationship with them, and such individual does not seem to be "an alien," "not like everyone else," "dangerous" to them.

Thus, in order to resolve the "ethical dilemma" in the context of the migration crisis, we must focus on three key statements: the "constancy" of migrants as active members of society, the rejection of the mononational and monocultural paradigm of society and the development of an individualized approach and deactivation of group stereotypes concerning migrants.

\section{CONCLUSIONS}

The conducted research allowed us to draw to the following conclusions:

- the concept of "ethics" in relation to the issue of migrants needs to be clarified: ethics (in the context of the migration context) is a set of norms, principles and rules of behavior and interaction of an individual and society in a new social and cultural environment, as well as the interaction of an individual with members of the same or a different "alien" group;

- the associative experiment clearly demonstrated that such impersonal, neutral lexical units as "migrant" and its plural form "migrants," 
"refugee" and "refugees" provoke mainly negative associations (criminal, alien, terrorist, Islamist, etc.), while visual images of a female refugee, refugee children, migrant families form clearly neutral associations (Syrians, Arabs) or provoke empathy (family, beggars, poor, homeless). Although in interviews, respondents also noted that migrants as a phenomenon create a sense of danger, insecurity and anxiety, the vast majority of respondents (113 out of 124) admitted that they are personally acquainted with migrants and refugees (neighbors, colleagues, friends), whose company they enjoyed and never refer any previously mentioned associations to them.

- in the course of interviews we found out that the main information source about the situation with migrants was mass media. We analyzed the major newspapers - Hürriyet, The Sun, The Daily Express, Annahar, etc., and came to the conclusion that two-thirds of all materials are either strictly formal (statistics) or contain evaluative judgments, which indirectly affects the formation of negative social stereotypes about migrants and refugees and creates obstacles for the successful integration and adaptation of migrants and refugees into their new social environment.

- as part of the psychological experiment, we suggested the so-called "ethical dilemma" in the context of the migration issue and proposed ways to resolve this dilemma, namely: 1 . The perception of migrants as a "constant" of modern society, rather than temporary "inconvenience;" 2. The rejection of the mononational and monocultural paradigm of society with the vector to a multi-ethnical and multicultural society, as well as; 3. The development of an individualized approach to migrants and the deactivation of group stereotypes about migrants.

We suggest that the following problems deserve more attention in further research:

- the issue of the ethics in migration, as a section of applied ethics, which can and should be presented in the form of basic ethical principles;

- the continuation of the associative experiment and a series of interviews with the aim of analyzing the experience of each country (regional case-study) according to the given criteria;

- the potential of art (both visual and non-visual) for the establishment of positive stereotypes regarding migrants. 


\section{BIBLIOGRAPHY}

Bartlett R. C., Collins S. D. 2012. Aristotle's Nicomachean Ethics, Chicago: The University of Chicago Press.

Habermas J. (trans. Lenhardt C. and Weber Nicholsen S.). 1983. Moral Consciousness and Communicative Action, Cambridge-Massachusetts: MIT-Press.

Lewis R.D. 2006. When Cultures Collide, London: Nicholas Brealey International.

Lippmann W. 1921. Public Opinion, New Brunswick-London: Transaction Publishers.

McGarty C., Yzerbyt V.Y., Spears R. 2002. Stereotypes as Explanations: The Formation of Meaningful Beliefs about Social Groups, London-New York: Cambridge University Press.

Moving Stories: International Review of How Media Cover Migration (ed. A. White). 2015. London: Ethical Journalism Network. Retrieved from https://ethicaljournalismnetwork.org/ wp-content/uploads/2018/05/moving-stories-ejn.pdf.

Weaver G.R. 2000. Culture, Communication, and Conflict: Readings in Intercultural Relations, Boston: Pearson Pub.

Wellman H.C., Cole P. 2011. Debating the Ethics of Immigration. Is There a Right to Exclude?, Oxford: Oxford Press.

Mel'nik G.S. 1996. Mass-Media: Psihologičeskie processy i èffekty, Sankt-Peterburg.

Metelev I.S. 2010. Social'naâ ètika i migracionnyj opyt, Omsk. 